UNIVERSIDADE FEDERAL DO PARANÁ

THIAGO BUENO SAAB

A POBREZA E O CURRÍCULO: PERMANÊNCIAS E AUSÊNCIAS NOS DOCUMENTOS OFICIAIS DE GEOGRAFIA.

CURITIBA

2016 
THIAGO BUENO SAAB

\section{A POBREZA E O CURRÍCULO: PERMANÊNCIAS E AUSÊNCIAS NOS DOCUMENTOS OFICIAIS DE GEOGRAFIA}

Artigo apresentado como requisito para a conclusão do Curso de Especialização em Educação, Pobreza, e Desigualdade Social, da Universidade Federal do Paraná.

Orientadora: Profa. Dra. Marcia Andréia Grochoska

\section{CURITIBA}




\section{A pobreza e o currículo: permanências e ausências nos documentos oficiais de Geografia.}

Thiago Bueno Saab

\section{RESUMO}

O presente artigo visa realizar uma análise sobre os documentos oficiais (PCN's; DCN's; e o Caderno de expectativas) de Geografia, visando a compreensão de como estes abordam a produção histórica da pobreza e se as vivências dos coletivos pauperizados estão inseridas nos referidos documentos. Assim, evidenciase o intuito de responder o seguinte questionamento: como o currículo formal da disciplina de Geografia do ensino fundamental II abrange as vivências da pobreza e de que forma possibilita ou não a compreensão da produção histórica dessa. A metodologia que alicerçou esta pesquisa caracteriza-se como qualitativa e tem como suporte teórico bibliografias cujo vínculo principal se refira à temática de análise. Não obstante, lançou-se mão de uma análise documental dos currículos da disciplina de Geografia do Ensino Fundamental II (PCN's - 1998, e DCN's - 2013, e os Cadernos de Expectativas de Aprendizagem do Paraná - 2012). Como resultado, percebeu-se que não há nos documentos oficiais analisados qualquer debate sobre as raízes da pobreza, bem como não há a inserção das vivências materiais e imateriais dos coletivos pauperizados.

Palavras-chave: Pobreza. Currículo. Documentos oficiais de Geografia.

\section{INTRODUÇÃO}

O capital cria um mundo à sua imagem e semelhança, portanto, a formação escolar tende a reproduzir o paradigma do sistema capitalista de produção, haja vista que a escola se constitui como um dos aparelhos ideológicos do Estado.

Desse modo, o currículo - o qual pode ser compreendido como os percursos e trajetórias trilhadas pelo estudante durante os anos de escolarização - ratificará a lógica societal excludente do modo de produção capitalista, corroborando com o que Althusser (1987) indica, que a escola é um dos aparelhos ideológicos do Estado, servindo como instrumento de dominação.

A estes aspectos, Freire (1987) nominou como pedagogia bancária e Gadotti (2008) de pedagogia inocente, as quais formam discentes dóceis e submissos aos valores vigentes. Logo, para romper com este processo, a educação deve ir para "além do capital", conforme sugere Meszáros (2008), incluindo nos currículos as 
vivências da pobreza, e como ocorre a produção política, histórica, social e econômica desta.

Justifica-se o estudo da presente temática pelo anseio de se compreender que tipo de formação é propiciada aos alunos na disciplina de Geografia, haja vista que tal disciplina busca elucidar as relações espaciais existentes, dentre as quais se insere o entendimento da produção da pobreza como fruto do desenvolvimento desigual e combinado da realidade, conceito formulado por Trotsky (1977), ou como Soja (1993) sugere, um desenvolvimento geograficamente desigual, formando o que Santos (1999) nomina como territórios luminosos e opacos.

A partir do exposto, objetiva-se empreender uma revisão de literatura sobre como os currículos abarcam a pobreza, e como estes conhecimentos se delineiam e materializam nas práticas escolares. Portanto, este artigo tem como objetivo responder o seguinte questionamento: Como o currículo formal da disciplina de Geografia do ensino fundamental II abrange as vivências da pobreza e de que forma possibilita ou não a compreensão da produção histórica da mesma?

As vivências podem ser compreendidas como a cultura material e imaterial destes coletivos pauperizados e do próprio sujeito e sua condição de ser pobre. Nesse sentido, é fundamental delinear o entendimento da pobreza para além da rasa leitura da "falta de algo", mas como a condição de uma produção engendrada pelo próprio modus operandi, a qual pode ser considerada como histórica, política, social, econômica, e que possui uma espacialidade, sendo, pois, geográfica.

Para responder a esta pergunta, lança-se mão da análise dos documentos oficiais de Geografia, sendo estes os PCN's - Parâmetros Curriculares Nacionais (1998), as DCN's - Diretrizes Curriculares Nacionais (2013), e os Cadernos de Expectativas (2012). Esta análise busca empreender uma investigação sobre como estes documentos oficiais abordam, na Geografia, a produção histórica e estrutural da pobreza, bem como se as vivências destes grupos, os pobres, estão de alguma forma inseridas nestes documentos acima mencionados. Por final, elaborou-se uma síntese das principais dimensões apreendidas na presente investigação, a qual consta no Quadro 1.

Os Cadernos de Expectativas de Aprendizagem expressam aquilo que é essencial ao estudante conhecer ao final de cada ano do Ensino Fundamental e ao final do Ensino Médio, dentro de cada conteúdo básico definido nestes Cadernos De Expectativas (PARANÁ, 2012). Ressalta-se que esta pesquisa assenta-se na 
análise dos documentos oficiais existentes, os quais se efetivam por meio de seus conteúdos e suas respectivas expectativas de aprendizagem. Dessa forma, esta pesquisa se apresenta como qualitativa e tem como suporte teórico bibliografias que tenham vínculo com a temática de análise.

Convém mencionar que o motivo da escolha de tais documentos justifica-se pelo entendimento de que parte das trajetórias vivenciadas pelos alunos se dá por meio do dito "currículo formal", composto por estes documentos oficiais.

\section{REVISÃO DE LITERATURA}

2.1 Currículo: notas para uma breve discussão.

Este tópico inicia-se com apontamentos em relação ao que se entende de um conceito fulcral para o presente artigo, sendo este, a pobreza. Arroyo (2010) desvela algumas visões arraigadas no imaginário social sobre a pobreza e os pobres, das quais destacam-se o entendimento destes como: carentes, marginais, excluídos e/ou inconscientes. Cada uma destas formas de pensar oculta o entendimento da produção da pobreza como uma questão política e social.

Assim, o autor supracitado lança os seguintes questionamentos:

Diante dessas formas de ocultamento, se impõe perguntar-nos: Essa diversidade de formas de ocultar as desigualdades e suas vítimas tem conseguido convencer os coletivos feitos tão desiguais em nossa história de que não passam de carentes, marginais, excluídos, inconscientes? Terão se convencido de que não cabe ao Estado, a suas instituições e políticas enfrentar as desigualdades de suas formas de viver, mas apenas corrigir, suprir carências, moralizá-los e até abrir as portas, dar acesso a instituições inclusivas? (ARROYO, 2010, p. 1392).

Destarte, faz-se mister compreender como a pobreza se insere (ou não) nos documentos oficiais do ensino fundamental II, da disciplina de Geografia, e como são conduzidas as trajetórias realizadas pelos discentes na disciplina supracitada. Desta forma, pode-se asseverar que a própria concepção de currículo é polissêmica, na medida em que abriga uma variada gama de entendimentos. Para Favacho (2012), a concepção de currículo como campo de disputa não é nova, pois veio à tona, internacionalmente, nos anos de 1970 e, no Brasil, nos anos de 1980, tendo se 
revelado como um importante balizador para a análise das relações de poder que envolvem os currículos.

Em função de sua recente presença no campo educacional brasileiro, Souza (2008) afirma que, para muitos professores, esse é um termo confuso e impreciso, pois o relacionam aos programas escolares ou planos de ensino. De forma correlata, há professores que associam o termo ao sentido restrito de grade curricular (distribuição do número de aulas de cada matéria em cada série).

No mesmo caminho, Moreira (1990) evidencia que, em marcos temporais distintos, se encontram apontamentos de significados diferentes para o termo currículo, de modo que a maioria destes remetem à ideia de currículo como conteúdos ou experiências de aprendizagem, planos, objetivos educacionais, e, até mesmo, de avaliação.

Entretanto, há autores que postulam outros vieses para a leitura do que se constitui o currículo, os quais corroboram com o entendimento de que 0 :

O currículo é a ligação entre a cultura e a sociedade exterior à escola e à educação, entre o conhecimento e cultura herdados e a aprendizagem dos alunos; entre a teoria - ideias, suposições e aspirações - e a prática possível, dadas determinadas condições. (SACRISTÁN, 1999, p.61).

Do mesmo modo, Jesus (2008) assinala que o currículo não pode ser dissociado de seu caráter ideológico, tornando-se, assim, um terreno propício para a transformação ou manutenção das relações de poder e, portanto, das mudanças sociais. Ainda, a autora supracitada compreende que há um encontro entre ideologia e cultura, sendo estas mediadas por relações de poder na própria sociedade, ressaltando-se, naturalmente, na educação.

Complementando este ponto de vista, Jesus (2008, p.2639) apregoa que o

Currículo também é inseparável da cultura. Tanto a teoria educacional tradicional quanto a teoria crítica vêem no currículo uma forma institucionalizada de transmitir a cultura de uma sociedade. Sem esquecer que, neste caso, há um envolvimento político, pois, o currículo, como a educação, está ligado à política cultural. Todavia, são campos de produção ativa de cultura e, por isso mesmo, passíveis de contestação.

Como não faz parte do escopo deste artigo empreender uma longa análise sobre o conceito de currículo, afirma-se que neste texto adotar-se-á o entendimento 
de currículo como as trajetórias e caminhos pela aprendizagem formal e informal ${ }^{1}$ trilhados pelo aluno, desvinculando-se da ideia de que apenas os documentos oficiais ou uma lista de conteúdos a serem trabalhados podem evocar a compreensão do que seja o currículo.

Por conseguinte, no próximo tópico apontar-se-ão quais as vinculações existentes entre o currículo e a pobreza, e como estas se materializam na realidade escolar.

\subsection{Pobreza e currículo.}

Harvey (1992) indica que há um processo em curso no qual a pobreza avança numericamente, e ainda acrescenta que o esfacelamento das conquistas sociais da classe trabalhadora tem criado uma legião de pessoas desprovidas de trabalho e de quase todas as condições que assegurem a vida e a dignidade humanas, como os direitos básicos de garantia à alimentação, saúde e educação.

Antunes (2001) relembra que o século XX se iniciou como o século do emprego das massas e terminou com uma crescente onda de desemprego das mesmas. Dessa maneira, sabe-se que, na atualidade, a educação está atrelada ao mercado de trabalho, e como Lopes (2010) defende, tal mercado surge com outras modalidades de profissão e amplas perspectivas que exigem competências, habilidades psíquicas e motoras diferentes do mercado de trabalho do século XX.

Saab e Antonello (2015) também ressaltam que, com o advento da Reestruturação Produtiva do Capital $^{2}$, as competências e habilidades que o aluno deve desenvolver durante a vida escolar foram ressignificadas para atender às novas mudanças no mundo do trabalho. Nessa seara do desenvolvimento de habilidades e competências dos alunos, Mészáros (2008) alega que uma das funções da educação é produzir tanta conformidade ou consenso em relação à ideologia dominante quanto for capaz.

O caráter reformista das mudanças nos sistemas educacionais não rompe com a lógica da exclusão. Antes, corrobora com a manutenção da exclusão da esmagadora maioria da humanidade do âmbito da ação como sujeitos, e condena-

\footnotetext{
${ }^{1}$ Daquilo que não está inscrito nas expectativas de aprendizagem.

${ }^{2}$ Processo iniciado com a crise do Fordismo na década de 1970 que culminou em um novo modelo produtivo, o qual Harvey (1992) nomina como acumulação flexível.
} 
os a serem apenas considerados como objetos, em nome da suposta superioridade da elite: uma superioridade meritocrática, tecnocrática e empresarial, induzindo a preservação dos padrões tidos como civilizados, contra a educação subversiva e libertadora.

O Neoliberalismo (no âmbito da Reestruturação Produtiva do Capital) foi o responsável pelo arrefecimento dos sindicatos, e de certo modo, pelo enfraquecimento dos movimentos sociais. E sobre esta questão, Arroyo (2003, p.35) faz a seguinte provocação:

Se os movimentos sociais repõem a centralidade dos sujeitos, como olhá-los? com um olhar escolar? como analfabetos? Como empregáveis? Se paramos nesse estreito olhar poderemos ficar satisfeitos com teorias de alfabetização ou de capacitação, porém estas não podem ser confundidas com teorias pedagógicas. Para que os sujeitos e seus processos formadores provoquem a teoria pedagógica temos de olhá-los no que eles têm de mais radicalmente humano.

Nesse sentido, Mészaros (2008) endossa que as escolas e o currículo servem, sobretudo, para reproduzir as desigualdades, principalmente expõem a disparidade entre as trajetórias pela aprendizagem de fato propiciadas para a educação das classes abastadas e a dos coletivos pauperizados, o que o autor supracitado indica como currículo mínimo, ou currículo dos pobres.

O mesmo autor advoga que a escola prepara os alunos para ratificarem 0 status quo, formando pessoas dóceis e submissas ao capital, as quais não contribuirão de fato para uma educação que prepare estes sujeitos para o real exercício da cidadania, que além das obrigações cívicas e da participação em seu meio, também implica na edificação (desde a tenra idade) do respeito e da tolerância, substantivos tão caros e pertinentes para a vida na sociedade atual.

Dessa maneira, faz-se fundamental a compreensão de como o currículo mínimo entrelaça-se com as medidas que precarizam e empobrecem ainda mais o mesmo, e consequentemente, a formação dos alunos.

A despeito destes fatos, Fonseca e Conceição (2012) alegam que o debate sobre educação como um direito humano e social vem ganhando espaço, principalmente, quando se tem uma educação baseada na exclusão. Durante muito tempo a escola possuía o papel de selecionar os melhores, e esta seleção excluía 
as mulheres, os negros, os indígenas, os deficientes e aqueles que eram considerados incapazes para suprir as necessidades do mercado de trabalho.

Pode-se considerar que os coletivos pauperizados eram vistos como inferiores pela sociedade dominante e só poderiam servir como mão de obra, pois não tinham capacidade de pensar, sendo o estudo um investimento desnecessário. Hoje, mesmo com todo o aparato da legislação, ainda são percebidas formas de exclusão, embora estas estejam mascaradas sob a forma de novos discursos. Assim, justifica-se mais veementemente a necessidade de se pensar a garantia do direito a educação a partir do binômio inclusão/exclusão.

Em relação aos coletivos excluídos, Arroyo (2010) afirma que estes devem ter o protagonismo da definição de suas demandas, e salienta que ignorar os coletivos vítimas das desigualdades e vê-los apenas como destinatários de políticas públicas termina empobrecendo a visão destes sujeitos pelo Estado, e prejudicando a eficácia destas políticas.

Destarte, Fonseca e Conceição (2012) assinalam que é de extrema importância dar visibilidade a esses desiguais dentro do ambiente escolar, para que não se corra o risco de, em nome de uma falsa diversidade, tratá-los uniformemente, desconsiderando seus diversos interesses. As diferenças precisam ser respeitadas e devem ser integradas em um contexto que não as anule.

Todavia, esta não é uma tarefa tão simples, conforme a reflexão abaixo indica:

As camadas urbanas em toda América Latina foram crescendo e ocupando o espaço urbano, de maneira caótica. Como se inserir? Como ter parte ou ter direito à cidade? A inserção social passou ao debate político, social e educativo. Passou a inquietar e mobilizar as próprias camadas populares urbanas. Processos diversos e dispersos de mobilização que vão contribuir para a conformação dos direitos sociais entre os excluídos. Entre esses direitos, com destaque o direito à educação e à escola pública. $A$ escola vai deixando de ser vista como uma dádiva da política clientelística e vai sendo exigida como um direito. Vai se dando um processo de reeducação da velha cultura política, vai mudando a velha autoimagem que os próprios setores populares carregavam como clientes agraciados pelos políticos e governantes. Nessa reeducação da cultura política tem tido um papel pedagógico relevante os movimentos sociais, tão diversos e persistentes na América Latina. (ARROYO, 2003, p.30). 
Arroyo (2003) advoga que retomar os vínculos entre a escola e os diversos movimentos sociais que representam os estratos excluídos da população ainda é valido para o pensar e o fazer pedagógicos escolares, especialmente quando se sabe a infância e a adolescência dos que frequentam as escolas públicas, e que estes estão entre aqueles que sofrem de maneira brutal a exclusão e as formas precárias do viver. E lança, ainda, a seguinte questão:

Como pensar currículos, conteúdos e metodologias, como formular políticas e planejar programas educativos sem incorporar os estreitos vínculos entre as condições em que os educandos reproduzem suas existências e seus aprendizados humanos? (ARROYO, 2003, p. 32).

O mesmo autor pontua que todo processo educativo, formal ou informal, tanto pode ignorar, como incorporar as formas concretas de socialização, de aprendizado, de formação e deformação a que estão submetidos os educandos. Ignorar esta realidade e se fechar nas questões curriculares e didáticas, terminará por isolar os processos didáticos escolares dos determinantes processos socializadores em que os setores populares se reproduzem desde a infância.

De tal modo, Arroyo (2003) reafirma que incluir essas vivências totalizantes nos currículos é importante, pois estas revelam à pedagogia o ser humano como totalidade existencial.

Ainda,

Desvendam e repõem dimensões perdidas na pesquisa, reflexão e ação pedagógica, tão centrada em formar o sujeito parcelado, instrumental, competente e hábil nos conhecimentos úteis, fechados. Revelam e repõem a educação como formação de sujeitos totais, sociais, culturais, históricos.

Recuperar essa concepção mais alargada de educação como formação e humanização plena pode ser uma das contribuições mais relevantes da pedagogia dos movimentos para a educação formal e não-formal. Para o repensar e agir pedagógicos. Alargar esse foco supõe ver os educandos para além de sua condição de aluno, de alfabetizandos, de escolarizandos... para vê-los como sujeitos de processos sociais, culturais, educativos mais totalizantes, onde todos estão imersos seja na tensa reprodução de suas existências tão precárias, seja na tensa inserção em lutas tão arriscadas onde tudo está em jogo (ARROYO, 2003, p.36, grifo do autor).

Na mesma linha, Fonseca e Pimenta (2012) advogam que um currículo diversificado, com metodologias variadas pode ser uma saída viável para propiciar 
uma formação holística aos desiguais existentes no mesmo espaço. Vale salientar que a condição de trabalho do professor é extremamente importante neste contexto, pois é preciso considerar que ele é quem precisará de um tempo maior para preparar os materiais e para estudar.

Na mesma perspectiva, Favacho (2012) destaca que o currículo não é apenas território de disputas teóricas, haja vista que os sujeitos (os docentes-educadores e os alunos-educandos) da ação educativa também rivalizam. Portanto, o autor supracitado salienta que os docentes e os discentes não se pensam apenas como ensinantes e aprendizes dos conhecimentos dos currículos, mas exigem ser reconhecidos como sujeitos de experiências sociais e de saberes que requerem ter vez no território de tais currículos.

Sobre a ação dos coletivos pauperizados e sua presença nos currículos, Arroyo (2003) alerta para o fato de que, quando cada área do currículo entende a história, a ciência, a tecnologia, o espaço, a vida, a produção literária e a cidade ou o campo do seu próprio ângulo, tende a deixar de fora saberes histórica e legitimamente construídos e acumulados pela pluralidade e diversidade de protagonistas que agem no social ou/e na natureza.

Logo, na condição de protagonistas, eles produzem saberes, outros saberes, com outros valores e significados, e sobretudo, outras lógicas não reconhecidas do pensar e do intervir, lógicas tidas como marginais às lógicas do saber escolar, do pensar científico e do intervir político.

Dessa maneira, quando os excluídos não são sujeitos ativos ou mesmo não se encontram presentes nos currículos, estes acabam por reproduzir a seguinte realidade:

A tolerância não garante direitos, tolera-se o diferente, aceita-se o
diferente, mas o que fazer para que seus direitos sejam efetivamente
garantidos. A escola vem tolerando a diversidade, pois a legislação a
obriga a aceitar, mas percebe-se que pouco avançou no sentido de
garantir a permanência dos desiguais na escola. A taxa de
reprovação é um exemplo claro do quanto ainda se tem que evoluir
para garantir uma educação de qualidade a todos, sem distinção de
etnia, credo, gênero ou condição social (FONSECA; PIMENTA, 2012,
p. 11).

Após uma sucinta exposição dos elementos que permitem interpretar 0 entrelaçamento entre o currículo e a pobreza - esta vista a partir da perspectiva de 
inclusão e exclusão da população com menor poder aquisitivo (pobres) no processo de ensino-aprendizado no Brasil, realizar-se-á um diagnóstico dos documentos oficiais de Geografia na tentativa de apreender como a pobreza insere-se nestes.

\subsection{Os documentos curriculares oficiais e a pobreza.}

Os apontamentos sobre os documentos oficiais - os focos da análise deste artigo - iniciar-se-ãocom uma sucinta apresentação de como se constituiu o processo de construção dos Parâmetros Curriculares Nacionais (1998), das Diretrizes Curriculares Nacionais da Educação Básica, as quais se apresentam com um novo formato, recebendo dentro do atual documento a nominação de "novas Diretrizes Curriculares Nacionais para a Educação Básica", as DCNs (2013), e dos Cadernos de Expectativas de Aprendizagem do Paraná (2012). A partir do que foi indicado, são estas diretrizes ${ }^{3}$ que estabelecem a base nacional comum de educação, responsável por orientar a organização, articulação, o desenvolvimento e a avaliação das propostas pedagógicas de todas as redes de ensino brasileiras.

No tocante aos PCN's (1998, p. 5), afirma-se que estes foram elaborados durante o primeiro mandato do então Presidente Fernando Henrique Cardoso (19941998), tendo recebido inúmeras críticas por endossarem a cartilha neoliberal imposta pelo banco mundial e pelo Fundo Monetário Internacional (F.M.I.), embora os PCN's preconizem que estes documentos,

[...] foram elaborados procurando, de um lado, respeitar diversidades regionais, culturais, políticas existentes no país e, de outro, considerar a necessidade de construir referências nacionais comuns ao processo educativo em todas as regiões brasileiras. Com isso, pretende-se criar condições, nas escolas, que permitam aos nossos jovens ter acesso ao conjunto de conhecimentos socialmente elaborados e reconhecidos como necessários ao exercício da cidadania (BRASIL, 1998, p.5).

No que versa sobre as DCN's (2013), as quais foram elaboradas no primeiro mandato da Presidente Dilma Rousseff (2011-2014), o discurso existente no documento indica que estas derivam de um amplo debate e buscam prover os

\footnotetext{
${ }^{3}$ Neste artigo optou-se por explorar primeiramente os documentos ancorados na legislação federal, e só posteriormente ingressar nas diretrizes estaduais do Paraná, Estado cuja presente análise se desdobra.
} 
sistemas educativos em seus vários níveis (municipal, estadual e federal) de instrumentos para que crianças, adolescentes, jovens e adultos que ainda não tiveram a oportunidade de se escolarizarem, possam se desenvolver plenamente, recebendo uma formação de qualidade correspondente à sua idade e nível de aprendizagem, respeitando suas diferentes condições sociais, culturais, emocionais, físicas e étnicas.

Do mesmo modo, as DCN's (2013) salientam que a necessidade da atualização das Diretrizes Curriculares Nacionais surgiu da constatação de que as várias modificações - como o Ensino Fundamental de nove anos e a obrigatoriedade do ensino gratuito dos quatro aos dezessete anos de idade deixaram as anteriores defasadas. O mesmo documento endossa que essas mudanças ampliaram consideravelmente os direitos à educação no país.

Assim, este novo documento apresenta as seguintes características:

É por isto que, além das Diretrizes Gerais para Educação Básica e das suas respectivas etapas, quais sejam, a Educação Infantil, Fundamental e Média, também integram a obra as diretrizes e respectivas resoluções para a Educação no Campo, a Educação Indígena, a Quilombola, para a Educação Especial, para Jovens e Adultos em Situação de Privação de Liberdade nos estabelecimentos penais e para a Educação Profissional Técnica de Nível Médio. Além disso, aqui estão presentes as diretrizes curriculares nacionais para a Educação de Jovens e Adultos, a Educação Ambiental, a Educação em Direitos Humanos e para a Educação das Relações ÉtnicoRaciais e para o Ensino de História e Cultura Afro- Brasileira e Africana (BRASIL, 2013, p.4).

Como não é o intuito do presente artigo realizar um amplo debate sobre o processo que culminou na materialização destes documentos, bem como não se constitui como desígnio deste demonstrar o sustentáculo teórico e prático que os embasaram, passa-se agora ao terceiro documento, o Caderno de Expectativas de Aprendizagem elaborado pela Secretaria de Educação do Paraná, em 2012, no primeiro mandato (2011-2014) do Governador Carlos Alberto Richa (Beto Richa).

Por conseguinte, a SEED - Secretaria de Estado de Educação (2012), assinala que as Expectativas de Aprendizagem expressam aquilo que é essencial ao aluno conhecer ao final de cada ano do Ensino Fundamental e ao final do Ensino Médio, dentro de cada conteúdo básico definido nas Diretrizes. Nesse sentido, por se referirem a esses conteúdos, as Expectativas são amplas, e se apresentam como um norte, um objetivo final a ser atingido, uma vez que é prerrogativa da 
mantenedora definir o desenvolvimento básico esperado para todos os alunos, em todos os anos.

Cabe pontuar que o processo de construção do Caderno de Expectativas teve o início de seu delineamento a partir de discussões realizadas no ano de 2011. Assim, o documento foi elaborado de maneira coletiva, com a participação dos professores da rede e dos técnicos-pedagógicos que atuam nos Núcleos Regionais da Educação do Paraná, apresentando a sistematização de 11.720 contribuições dos professores, debatidas durante a Semana Pedagógica de julho de 2011, bem como as contribuições dos técnicos-pedagógicos dos NRE, discutidas na formação continuada.

Elucida-se que a finalidade para qual se destinam pode ser expressa da seguinte maneira:

As Expectativas de Aprendizagem, entendidas como elementos balizadores e indicadores de objetivos a serem atingidos, notabilizam-se pelo seu potencial de qualificação e democratização do ensino público ofertado à população, uma vez que: 1) contribuem para a qualificação do ensino, na medida em que, coerentes com as Diretrizes Curriculares Orientadoras da Educação Básica para a Rede Estadual, expressam claramente, embora de forma ampla, os conteúdos fundamentais que devem ser ensinados/aprendidos em cada uma das disciplinas do currículo escolar; 2) podem ser consideradas instrumentos pedagógicos de democratização do ensino, ao serem apropriadas por todo 0 conjunto de estabelecimentos e professores, na medida em que asseguram a todos uma mesma baliza geral de temas/conteúdos que devem ser ensinados/ aprendidos (PARANÁ, 2012, p.5)

Destarte, após as resumidas explanações acerca dos documentos supracitados, passa-se agora para a análise propriamente dita, e para isto, elencase os seguintes elementos que sustentarão a apreciação dos dados verificados.

É de fundamental importância ressaltar que se busca investigar se estes documentos abordam as raízes históricas da produção da pobreza, o modo como relacionam os fatores que culminam na materialização deste processo, e se têm o fito de verificar como se dá (ou não) a inserção destes coletivos pauperizados como parte integrante do modo de produção vigente. Objetiva-se ainda verificar se há a presença das vivências e saberes dos pobres no conteúdo presente nestes documentos, se tais documentos consideram neste processo o protagonismo 
destes, ou se os discursos obedecem à uma lógica vertical e distanciada da empiria dos coletivos dos pobres.

A síntese dos dados abordados nos documentos apresentados anteriormente encontra-se sistematizados no Quadro 1, tendo como proximidade as noções que nortearam as discussões-problemas deste presente artigo. Cabe a menção de que estes elementos servem como subsídio para se estabelecer uma análise que permita o desvelamento do teor dos diferentes documentos.

Das dimensões acima expostas, apontar-se-ão os pontos de convergência e de divergência entre os documentos que perfazem o escopo desta análise. A concepção dos documentos constitui-se como uma das extensões apresentadas, de modo que os PCN's divergem das DCN's e dos Cadernos de Expectativas, tendo em vista que o primeiro está calcado em uma lógica neoliberal, de competências e habilidades, marcas da reestruturação produtiva do capital, como defendem Saab e Antonello (2015) e os dois últimos, ao contrário, ambicionam uma formação crítica e cidadã, calcada em autores signatários do Materialismo Histórico-Dialético.

Quadro 1 - Comparativo dos documentos oficiais de Geografia e sua correlação com a pobreza.

\begin{tabular}{|c|c|c|c|}
\hline $\begin{array}{l}\text { Documento } \\
\text { Dimensões }\end{array}$ & PCN's (1998) & DCN's (2013) & $\begin{array}{c}\text { Cadernos de } \\
\text { Expectativas } \\
(2012)\end{array}$ \\
\hline Concepção & Neoliberalismo $^{4}$ & $\begin{array}{c}\text { Materialismo Histórico- } \\
\text { Dialético }^{5}\end{array}$ & $\begin{array}{c}\text { Materialismo Histórico - } \\
\text { Dialético }\end{array}$ \\
\hline Princípios & Reforma do Capitalismo & Geografia Crítica & Geografia Crítica \\
\hline Visão & $\begin{array}{l}\text { Crítica a Geografia } \\
\text { Tradicional e a Crítica, } \\
\text { engendra políticas de } \\
\text { Qualidade Total }\end{array}$ & $\begin{array}{c}\text { Ancorada nos princípios } \\
\text { de autonomia individual } \\
\text { e coletiva }\end{array}$ & $\begin{array}{c}\text { Geografia Crítica como } \\
\text { linha teórica e o espaço } \\
\text { geográfico como objeto } \\
\text { de estudo }\end{array}$ \\
\hline Conteúdos & $\begin{array}{l}\text { Aborda principalmente } \\
\text { questões relativas à } \\
\text { presença e ao papel da } \\
\text { natureza e sua relação } \\
\text { com a ação dos } \\
\text { indivíduos, dos grupos } \\
\text { sociais e, de forma } \\
\text { geral, da sociedade na } \\
\text { construção do espaço }\end{array}$ & $\begin{array}{c}\text { Não realiza } \\
\text { pontualmente } \\
\text { considerações sobre os } \\
\text { conteúdos }\end{array}$ & $\begin{array}{l}\text { Os conceitos básicos } \\
\text { da Geografia: } \\
\text { paisagem, sociedade, } \\
\text { território, natureza, } \\
\text { lugar e região orientam } \\
\text { as discussões dos } \\
\text { conteúdos } \\
\text { estruturantes. Além dos } \\
\text { conceitos básicos, as }\end{array}$ \\
\hline
\end{tabular}

${ }^{4}$ Para Saab e Antonello (2015), a grosso modo, o neoliberalismo é marcado pelas políticas macroeconômicas capitalistas que defendem a participação e intervenção mínima do Estado na organização social e na economia.

${ }^{5}$ Para Stálin (1938), o materialismo dialético é a concepção filosófica do Partido marxista-leninista. Chama-se materialismo dialético, porque o seu modo de abordar os fenômenos da natureza, seu método de estudar esses fenômenos e de concebê-los, é dialético, e sua interpretação dos fenômenos da natureza, seu modo de focalizá-los, sua teoria, é materialista. 


\begin{tabular}{|c|c|c|c|}
\hline & $\begin{array}{c}\text { geográfico. Também } \\
\text { estuda as diferentes } \\
\text { relações entre as } \\
\text { cidades e o campo em } \\
\text { suas dimensões } \\
\text { sociais, culturais e } \\
\text { ambientais. }\end{array}$ & & $\begin{array}{c}\text { relações presentes nas } \\
\text { categorias de análise } \\
\text { Sociedade-Natureza e } \\
\text { Espaço-Tempo. }\end{array}$ \\
\hline Avaliação & $\begin{array}{c}\text { A avaliação deve ser } \\
\text { planejada } \\
\text { relativamente aos } \\
\text { conhecimentos que } \\
\text { serão } \\
\text { recontextualizados e } \\
\text { utilizados em estudos } \\
\text { posteriores. }\end{array}$ & $\begin{array}{c}\text { A avaliação da } \\
\text { aprendizagem no } \\
\text { Ensino Fundamental e } \\
\text { no Ensino Médio, de } \\
\text { caráter formativo } \\
\text { predominando sobre o } \\
\text { quantitativo e } \\
\text { classificatório. }\end{array}$ & Não aborda \\
\hline $\begin{array}{c}\text { Formação } \\
\text { Docente }\end{array}$ & $\begin{array}{l}\text { Formação na defesa do } \\
\text { status quo capitalista }\end{array}$ & $\begin{array}{l}\text { Formação crítica e } \\
\text { cidadã }\end{array}$ & $\begin{array}{l}\text { Formação crítica e } \\
\text { cidadã }\end{array}$ \\
\hline $\begin{array}{c}\text { Educação em } \\
\text { Direitos. }\end{array}$ & $\begin{array}{c}\text { Defesa da Pluralidade } \\
\text { étnica }\end{array}$ & $\begin{array}{c}\text { Estabelece um capítulo } \\
\text { para as Diretrizes } \\
\text { Nacionais para a } \\
\text { Educação em Direitos } \\
\text { Humanos }\end{array}$ & $\begin{array}{l}\text { Defesa da Pluralidade } \\
\text { étnica }\end{array}$ \\
\hline
\end{tabular}

Fonte: PCN's (1998), Caderno de Expectativas (2012), DCN's (2013)

Org: o autor (2016)

No universo da Geografia, enquanto os PCN's abordam a realidade a partir do prisma de um reformismo do capitalismo, as DCN's e os Cadernos de Expectativas aportam-se na perspectiva da Geografia Crítica. No tocante aos conteúdos, os PCN's centram-se na relação homem $x$ natureza, as DCN's não realizam apontamentos sobre este quesito, e os Cadernos de Expectativas levam em consideração os conceitos e categorias de análise geográficas.

A avaliação, uma das dimensões analisadas, tem como pressuposto o caráter formativo nos PCN's e nas DCN's, enquanto o Caderno de Expectativas não explora este item, tendo em vista que foge à finalidade deste.

Na sequência, a formação docente extraída dos presentes documentos leva a crer que, nos PCN's, almeja-se uma formação que defenda o status quo capitalista, e nas DCN's e nos Cadernos de Expectativas, pela sua própria formulação, anseiase pela concretização de uma formação crítica e cidadã.

Por final, a última dimensão analisada foi a Educação em Direitos, a qual está ausente dos PCN's, porém, é amplamente defendida pelas DCN's, tendo este um capítulo inteiro destinado ao debate deste item. Já o Caderno de Expectativas realiza a defesa da Pluralidade Étnica.

Especificamente sobre o universo que envolve pobreza, a grosso modo, nenhum dos três documentos trazem apontamentos em especial sobre como esta é 
produzida, e estes ignoram completamente a existência da vivência destes coletivos pauperizados.

Em relação ao Caderno de Expectativas de Geografia, as únicas menções sobre a pobreza realizadas em todo o corpo do documento são formuladas pensando nos conhecimentos que os discentes devem possuir ao fim de cada ciclo: "[...] 34 - Verifique as desigualdades sociais no território brasileiro e paranaense [...]" (PARANÁ, 2012, p.54); "[...] 77- compreenda as desigualdades sociais existentes no espaço geográfico [...]" (PARANÁ, 2012, p.55); e "[...] 98 - compreenda os indicadores sociais e econômicos da desigual distribuição de renda nos diferentes continentes [...]" (PARANÁ, 2012, p.57).

Entretanto, em momento algum há qualquer debate sobre a concepção do conceito de pobreza, e muito menos esboça-se qualquer referência sobre a inclusão das vivências da pobreza no processo de ensino-aprendizagem em Geografia, portanto, não se aborda a pobreza como um processo que faz parte das relações sociais de produção do modo de produção capitalista.

Nos PCN's (1998) percebe-se o mesmo fato, com a ausência completa do debate sobre a pobreza, bem como pelo silenciamento de suas experiências. No entanto, há de se mencionar que, neste, tal característica se apresenta de maneira ainda mais grave, pois este se configura como um documento que ratifica a lógica excludente com o discurso de que a escola tem por função desenvolver algumas habilidades e competências nos discentes, processo tal que Saab e Antonello (2015) revelam como pertencente ao novo quadro engendrado na educação pela reestruturação produtiva do capital.

Não obstante, observa-se como o documento enfatiza as benesses da dita "globalização do capital”, como no exposto, "[...] um só mundo e muitos cenários geográficos, com Estados, povos e nações redesenhando suas fronteiras" (BRASIL, 1998, p.124).

De maneira semelhante, o documento novamente sai pela tangente ao designar como conteúdo a temática que versa sobre "[...] os espaços das minorias nacionais, étnicas e culturais" (BRASIL, 1998, p.107), mascarando o processo que mantém tais economias na margem da Divisão Internacional do Trabalho.

Por outro lado, as DCN's (2013) trazem o conteúdo de maneira crítica e propositiva, como se evidencia na sequência: 
Na perspectiva de contribuir para a erradicação das desigualdades e da pobreza, a busca da equidade requer que se ofereçam mais recursos e melhores condições às escolas menos providas e aos alunos que deles mais necessitem. Ao lado das políticas universais, dirigidas a todos sem requisito de seleção, é preciso também sustentar políticas reparadoras que assegurem maior apoio aos diferentes grupos sociais em desvantagem. (BRASIL, 2013, p.131)

Em tempo, as DCN's inovam ao dedicarem um capítulo apenas aos direitos humanos, compreendendo a pobreza como uma violação destes, como bem se expressa em ambas citações expostas a seguir:

As profundas contradições que marcam a sociedade brasileira indicam a existência de graves violações destes direitos em consequência da exclusão social, econômica, política e cultural que promovem a pobreza, as desigualdades, as discriminações, os autoritarismos, enfim, as múltiplas formas de violências contra a pessoa humana. Estas contradições também se fazem presentes no ambiente educacional (escolas, instituições de educação superior e outros espaços educativos) (BRASIL, 2013, p.515).

Destarte, estes direitos são compreendidos no art. $6^{\circ}$ das DCN's (2013), como o alicerce que sustenta as políticas educacionais e pedagógicas, evidenciando seu caráter político, no,

[...] reconhecimento dos direitos e deveres de cidadania, de respeito ao bem comum e à preservação do regime democrático e dos recursos ambientais; de busca da equidade no acesso à educação, à saúde, ao trabalho, aos bens culturais e outros benefícios; de exigência de diversidade de tratamento para assegurar a igualdade de direitos entre os alunos que apresentam diferentes necessidades; de redução da pobreza e das desigualdades sociais e regionais (BRASIL, 2013, p. 131).

Embora as DCN's (2013) possuam prerrogativas inovadoras, também é negligenciado no documento o teor do que se considera como pobreza, bem como não se vinculam as vivências dos coletivos dos pobres ao processo de ensinoaprendizagem.

Por fim, assinala-se que em nenhum dos três documentos analisados que versam sobre a disciplina de Geografia - a qual possui estreitos laços com 0 entendimento da produção da pobreza e suas respectivas vivências, sejam no aspecto do indivíduo ou no âmbito coletivo - foi encontrado qualquer debate no 
plano teórico sobre o conceito da mesma, bem como são nulas as contribuições destacadas por este estrato social. 


\section{CONSIDERAÇÕES FINAIS}

Conforme Arroyo (2010) evidencia, a escola brasileira não possuía o preparo para a inserção dos vinte por cento mais pobres neste espaço, no entanto, a partir da Constituição de 1988, a educação, o ingresso e a permanência se tornaram um direito, e por consequência, os coletivos pauperizados se constituíram como sujeitos de direitos.

Entretanto, após todo este período, o qual se estende da promulgação da constituição até a atualidade, poucos foram os avanços em direção à uma escola pública, gratuita e de qualidade. Embora os documentos oficiais e a lei garantam o ingresso do contingente populacional considerado como pobre, outros meios continuam ratificando o processo de exclusão deste segmento na escola, os quais podem ser percebidos pelos altos índices de evasão e repetência escolar.

Pode-se considerar, a partir da análise realizada, que parte deste quadro delineado acima, deriva do distanciamento entre o currículo ofertado para estes alunos e a realidade do dia-a-dia, principalmente para os estudantes pobres, pois não possui conexão com o universo da vivência destes, impossibilitando que os discentes compreendam como se dá a produção da pobreza, e também a sua inserção na sociedade, pois suas culturas materiais e imateriais são negligenciadas, silenciadas e excluídas dos currículos educacionais, os quais perfazem as trajetórias destes alunos.

Destarte, a partir do que se verificou na análise dos documentos oficiais de Geografia, fica evidente que não há a inserção de qualquer debate sobre as raízes da pobreza e/ou as origens de sua produção, as quais podem ser consideradas como políticas, econômicas, sociais, culturais, e estão situadas no tempo e espacialmente, vinculando-se de maneira irrefutável com a história e a geografia.

Por conseguinte, conclui-se que a garantia e a efetivação de uma escola pública, gratuita, de qualidade, plural e diversa são letras mortas na constituição, verdadeiros constructos, pois não se viabilizam na prática. E como proposição para os currículos, assevera-se que todo ser humano tem o direito de compreender como se dá a sua inserção na realidade e as origens históricas que culminaram neste processo, portanto, faz se absolutamente necessário que os currículos não só 
abordem as origens da produção da pobreza em seus vários matizes, bem como considerem a realidade material e imaterial concebida por este segmento social.

\section{REFERÊNCIAS}

ALTHUSSER, L. Aparelhos Ideológicos de Estado. 3 ed. Rio de Janeiro: Edições Graal, 1987.

ANTUNES, R. Trabalho e precarização numa ordem neoliberal. In: GENTILI, P; FRIGOTTO, G. (Org.) A cidadania negada: políticas de exclusão na educação e no trabalho. 2. ed. Buenos Aires: Clacso, 2001, p.35-48.

ARROYO, M.G. Pedagogias em movimento - o que temos a aprender dos Movimentos Sociais?. Currículo sem Fronteiras, Belo Horizonte, v. 3, n. 1, p. 2849, jan./jun. 2003.

Políticas educacionais e desigualdades: à procura de novos significados.

Educação \& Sociedade, Campinas, v. 31, n. 113, p. 1075-1432, 2010.

BRASIL, Parâmetros Curriculares Nacionais (5aa a $8^{\text {a }}$ séries). Brasília: MEC/SEF, 1998.

Ministério da Educação. Secretaria de Educação Básica. Diretrizes

Curriculares Nacionais Gerais da Educação Básica. Brasília: MEC, SEB, DICEI, 2013.

FAVACHO, A. P. O que há de novo nas disputas curriculares?. Educ. Soc., Campinas, v. 33, n.120, set. 2012.

FONSECA, J. A. L.; PIMENTA, R. W. S. A chegada dos desiguais à escola: novas formas de inclusão/exclusão. In: ANPED SUL, 9., 2012, Caxias do Sul. Anais... Caxias do Sul: UCS, 2012.

FONSECA, J. A. L. ; CONCEICAO, C. M. C. . Desigualdade social e cotidiano escolar: reflexões sobre a educação como direito social e humano. In: ENDIPE, 16, 2012, Campinas. Anais... Campinas: Unicamp, 2012.

FREIRE, P. Pedagogia do oprimido, 17. ed. Rio de Janeiro: Paz e Terra, 1987.

MOREIRA, A. F. B. Currículos e programas no Brasil. Campinas: Papirus, 1990.

GADOTTI, M. Educação e poder: introdução à pedagogia do conflito. São

Paulo:Cortez, 2008.

HARVEY, D. Condição pós-moderna. Uma pesquisa sobre as Origens da Mudança Cultural. São Paulo: Edições Loyola, 1992. 
JESUS, A. R. de. Currículo e educação: conceito e questões no contexto educacional. Disponível em:

<http://www.pucpr.br/eventos/educere/educere2008/anais/pdf/642_840.pdf>. Acesso em: 06 set. 2016.

LOPES, G. G. F.C. A industrialização no Paraná e a educação profissional: o sistema SENAI/SESI (1970-1990). 2010, 102 f. Dissertação (Mestrado em Educação) - Universidade Estadual de Londrina, Londrina. 2010.

MÉSZÁROS, I. A educação para além do capital. São Paulo: Boitempo, 2008.

PARANÁ, Caderno de expectativas de aprendizagem. Curitiba: SEED, 2012.

SAAB, T.B; ANTONELLO, I.T. A reestruturação produtiva do capital e a formação escolar: o discurso presente nos livros didáticos de Geografia. Pegada, Presidente Prudente, v.1, n.16, p. 127-158, jul. 2015.

SACRISTAN, J. G. Poderes instáveis em educação. Tradução de Beatriz Affonso Neves. Porto Alegre: Artmed, 1999.

SANTOS, Milton. A natureza do espaço: espaço e tempo: razão e emoção. 3. ed. São Paulo: HUCITEC, 1999.

SOUZA, R. F. de. História da organização do trabalho escolar e do currículo no Século XX: (ensino primário e secundário no Brasil). São Paulo: Cortez, 2008.

SOJA, E. W. Geografias pós-modernas: a reafirmação do espaço na teoria social crítica. Rio de Janeiro: Jorge Zahar Ed., 1993.

STÁLIN, J.V. Sobre o materialismo dialético e o materialismo histórico. 1938. Disponível em: <https://www.marxists.org/portugues/stalin/1938/09/mat-diahist.htm>. Acesso em: 20 set. 2016.

TROTSKY, L. História da revolução russa. 2 e. Rio de Janeiro: Paz e Terra, 1977. 